Article

\title{
Neuro-Fuzzy System for Energy Management of Conventional Autonomous Vehicles
}

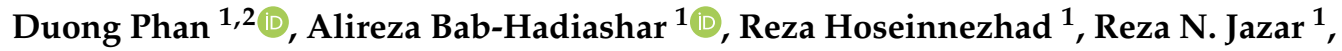 \\ Abhijit Date ${ }^{1}$, Ali Jamali ${ }^{3} \mathbb{D}$, Dinh Ba Pham ${ }^{2}\left(\mathbb{D}\right.$ and Hamid Khayyam ${ }^{1, *}$ \\ 1 School of Engineering, RMIT University, Melbourne, VIC 3083, Australia; \\ s3669474@student.rmit.edu.au (D.P.); alireza.bab-hadiashar@rmit.edu.au (A.B.-H.); \\ reza.hoseinnezhad@rmit.edu.au (R.H.); reza.nakahiejazar@rmit.edu.au (R.N.J.); \\ abhijit.date@rmit.edu.au (A.D.) \\ 2 Division of Mechatronics, Mechanical Engineering Institute, Vietnam Maritime University, Haiphong 180000, \\ Vietnam; bapd.vck@vimaru.edu.vn \\ 3 Faculty of Mechanical Engineering, University of Guilan, Gilan Province 4199613776, Iran; \\ ali.jamali@guilan.ac.ir \\ * Correspondence: hamid.khayyam@rmit.edu.au
}

Received: 5 February 2020; Accepted: 31 March 2020; Published: 5 April 2020

check for updates

\begin{abstract}
This paper investigates the energy management system (EMS) of a conventional autonomous vehicle, with a view to enhance its powertrain efficiency. The designed EMS includes two neuro-fuzzy (NF) systems to produce the optimal torque of the engine. This control system uses the dynamic road power demand of the autonomous vehicle as an input, and a PID controller to regulate the air mass flow rate into the cylinder by changing the throttle angle. Two NF systems were trained by the Grid Partition (GP) and the Subtractive Clustering (SC) methods. The simulation results show that the proposed EMS can reduce the fuel consumption of the vehicle by 6.69 and $6.351 / 100 \mathrm{~km}$ using the SC and the GP, respectively. In addition, the EMS based on NF trained by GP and NF trained by SC can reduce the fuel consumption of the vehicle by $11.8 \%$ and $7.08 \%$ compared with the case without the controller, respectively.
\end{abstract}

Keywords: autonomous vehicles; intelligent energy management system; neuro-fuzzy

\section{Introduction}

An Autonomous Vehicle (AV) was known as a vehicle that can manoeuvre by itself without human conduction [1,2]. They have been used with the aims of: (i) improving road safety, (ii) avoiding crashes, (iii) releasing driver time and business opportunities, and (iv) new potential market opportunities [1,3]. To find localization, map, path learning and tracking for itself, AV needs mobile navigation equipment on board. Software accuracy, sensor fusion and estimation are central parts of an AV's mobility [1]. Ten million AVs are expected on the roads by 2020 and companies could have a $\$ 7$ trillion annual revenue stream from the AV market in 2050 [4]. Intelligent EMSs can observe/sense and learn driver's behaviour, environmental and vehicle conditions to govern the operation of the vehicle autonomously to decrease the fuel usage of the vehicle and therefore its greenhouse gases emissions.

A number of researches have been conducted to improve the fuel economy to reduce the fuel usage along with the Internal Combustion Engine (ICE) of conventional vehicles [5,6] and Hybrid Electric Vehicles (HEVs) [7-9]. In this study, we focus on improving the energy efficiency of a conventional autonomous vehicle (CAV). Koot et al. [10] proposed an energy management approach which was used to produce and save the power of electric at proper times during the trip. The simulation results illustrated that the energy usage could be improved by $2 \%$ without using the prediction 
for driving cycles. In another study, the same authors [11] concentrated on utilizing regenerative braking protocols to decrease fuel consumption and emission levels. With the introduced method, the alternator-based power of the vehicle was regulated to maintain the torque of the engine in its higher efficiency operational area, which yielded an improvement in fuel consumption. Won et al. [12] derived an intelligent energy management method for vehicles which relied on making decisions on splitting the power automatically. By using the optimal approaches for two tasks, distributing the engine torque and charging the battery, the results showed that the fuel usage of the vehicle decreased. Poursamad and Montazeri [13] proposed a genetic-fuzzy control method to reduce energy consumption in non-autonomous vehicles. With the proposed controller, the operation of the engine was governed in an optimal area by adjusting the energy produced by the powertrain, and then it was exploited and saved. The results showed that fuel consumption was decreased without sacrificing vehicle performance by using the control strategy. Khayyam et al. [6] proposed a system for a conventional vehicle in terms of reducing fuel consumption by enhancing the efficiency of the engine. The simulation results showed that fuel usage can be improved by $5.6 \%$ with the designed system. Khayyam et al. [14] investigated an adaptive cruise control look-ahead system to improve efficient driving by keeping speed constantly at a current level. The system considered many factors including the slope of the road, wind profile and kinetic energy to determine the fuel consumption of the vehicle. The slope of the road which involved in the system was predicted by exploiting the look-ahead strategy. The results illustrated that the average energy consumption was improved by $3 \%$. Recently, Phan et al. [5] proposed an intelligent EMS for CAVs based on a fuzzy logic system and PID. With the investigation of the control system, the energy usage of vehicle was improved by around $9.58 \%$.

Most of the existing studies focus on using the fuzzy control method, which offers a practical alternative to conventional control approaches for solving the nonlinear automotive control problem. The prominent feature of the fuzzy controller was that there was not necessarily an explicit mathematical model of the system to be regulated. Furthermore, this controller can simulate the behaviour of expert drivers using if-then rules based on human experience and knowledge. However, the main problem is that there are no standard solutions for transferring the knowledge or experience of humans into fuzzy sets, rules and membership functions. Manual tuning based on human expertise was used to adjust control systems. In order to have optimal membership functions and output parameters of the fuzzy system, additional self-regulating and effective algorithms are needed for the tuning process.

An NF system was a model in which the training data was used by the neural network to determine the membership functions and fuzzy rules of the fuzzy inference system (FIS) automatically. The advantages of merging neural networks and fuzzy systems are shown in $[15,16]$. Neural networks have the learning ability required, as the weight of the connections between the nodes can be adjusted. Moreover, fuzzy logic systems supply a competent environment or computing framework based on the concepts of fuzzy set theory, fuzzy rules and fuzzy reasoning. The combination generates if-then rules through fuzzy inference and optimises the prediction performance by revising the parameters applied in the fuzzy rule by using the learning capabilities of the neural network. The fusion makes intelligent systems more adaptively to solve real-world problems.

\section{Vehicle Dynamics and Road Power Demand}

Several factors, including environmental conditions, driver behaviour and vehicle dynamics specifications, are needed to be involved in a thorough energy management approach for a CAV. In order to elevate the overall efficiency of the vehicle, models of factors affecting vehicle fuel usage need to be developed accurately. To fulfil this requirement, models for the road power demands of the vehicle, road geometry, wind condition, driver behaviour, and a model of the vehicle have been constructed. 
The speed of the vehicle was predefined as the standard driving cycle at given time $t$, which was used to estimate the road power demand of the vehicle as follows.

$$
P_{R P D}=F_{t} \cdot v_{t}+P_{a c}
$$

where $F_{t}$ is the total driving force required to overcome the resistive forces acting on the vehicle as illustrated in Figure 1. $P_{a c}$ is the air conditioning power.

As illustrated in Figure 1, the vehicle travels on the horizontal flat road with the uphill and downhill depicted by the slope angle of the road. The total driving force can be formulated as follows.

$$
F_{t}=F_{r f}+F_{d}+F_{s}+m \frac{d v_{t}}{d t}=c_{r} m g \cos \theta+c_{d} \cdot \frac{1}{2} \rho\left(v_{w}+v_{t}\right)^{2} \cdot A(\phi)+m g \sin \theta+m \frac{d v_{t}}{d t}
$$

where $F_{r f}$ is the road friction force, $F_{d}$ is the drag force, $F_{g}$ is the composition of the gravity in the direction against to the vehicle motion, $m$ depicts the vehicle mass, $\theta$ is the slope of the road, $c_{r}$ is the road friction coefficient, $v_{t}$ is the speed of vehicle at time $t, c_{d}$ is the drag coefficient, $\rho$ is the air density, $v_{w}$ is the absolute wind speed, and $A(\phi)$ is the cross-sectional area.

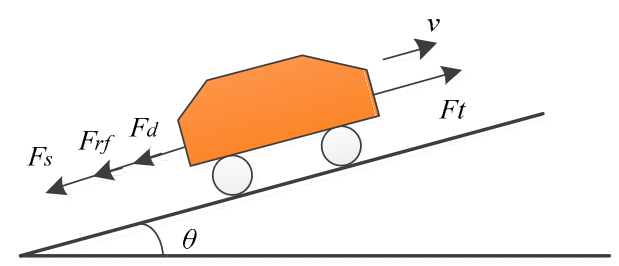

Figure 1. Illustration of forces acting on a vehicle travelled on a road with the slope angle $\theta$.

$P_{a c}$ is air conditioning power which represented as below.

$$
P_{a c}=\frac{d W_{a c}}{d t}=M C_{\text {room }} \frac{d T_{\text {room }}}{d t}
$$

where $M$ is the air mass within the cabin room, $T_{\text {room }}$ is the cabin temperature.

Substituting (2), and (3) into (1), we have:

$$
P_{R P D}=c_{r} m g \cos \theta \cdot v_{t}+c_{d} \cdot \frac{1}{2} \rho\left(v_{w}+v_{t}\right)^{2} A(\phi) \cdot v_{t}+m g \sin \theta \cdot v_{t}+M C_{\text {room }} \frac{d T_{\text {room }}}{d t}+m v_{t} \frac{d v_{t}}{d t}
$$

\subsection{Environmental Conditions}

Environmental conditions are among the factors that have significant effects on vehicle performance. However, these factors are often on unpredictable and occur randomly. Therefore, researchers do not have adequate data to develop a real-time operating system for a smart vehicle. To rectify this problem, the synthetic dataset was exploited to develop feasible solutions devised for fuel management of conventional and hybrid vehicles. The synthetic data of road, wind profile and air conditioning were generated by different models that are shown below.

\subsubsection{Model of Road Geometry}

The road geometry data, including a collection of straight segments, right and left turns, up and down hills, plays a vital role in designing the EMS for a vehicle. To produce the simulated road data which nearly resemble the real road, a model developed using a set of different probability distribution by Khayyam [17] was used. In this model, the number of road segments was randomly created by Poisson distribution. Exponential distribution was used to define the lengths of each road segment. Finally, the height of up and down hills was generated by Rayleigh distribution. The road constructed by this model was depicted in Figure 2, in which (a) shows the three-dimensional representation made 
by using stochastic models of road geometry [17], and (b) shows the slope of the road based on the model coves during $16.5 \mathrm{~km}$ driving.

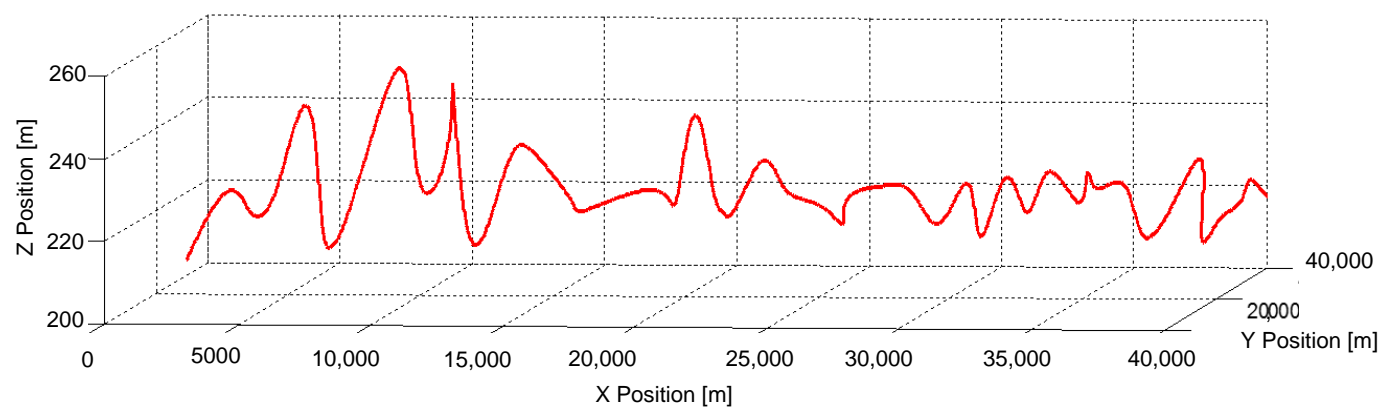

(a)

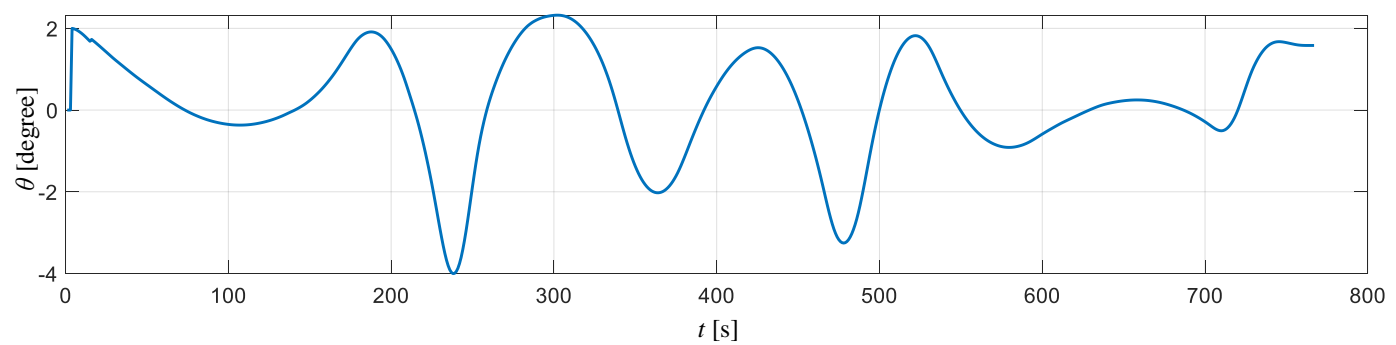

(b)

Figure 2. (a) Three-dimensional representation of the constructed by stochastic models of road geometry, (b) the slope of the road based on the model in [17].

\section{Model of Wind}

In this study, a wind profile was considered as a number of driving portions with different lengths, using a method to create iterative wind data, which was built based on the model investigated in [17]. To represent the wind profile the exponential, uniform and Weibull distribution were used. The wind profile exploited for simulations in this paper are depicted in Figures 3 and 4.

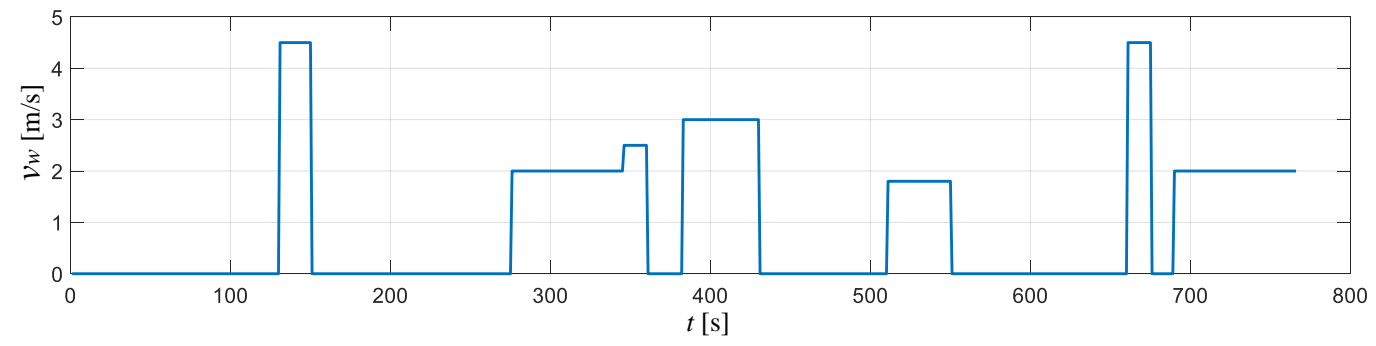

Figure 3. Wind speed created by the model described in [17].

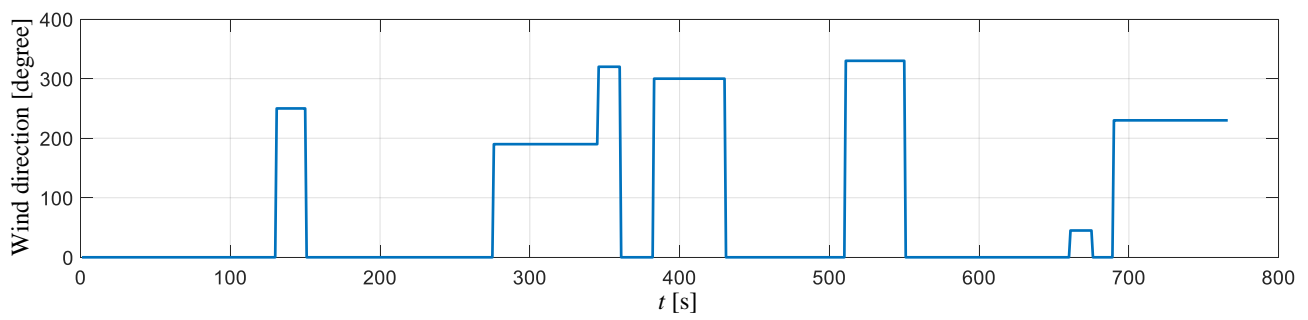

Figure 4. Wind direction generated by the model in [17]. 


\subsection{Model of Air Conditioning}

The power consumption used by an air conditioning (AC) system during travelling can be dynamically changed and escalate the energy usage of vehicle by $12 \%-17 \%$ [18]. Other auxiliary powers were quite small compared with the total power consumption of the vehicle. Therefore, in this study, only the AC power consumption was considered, and the rest of the losses related to other auxiliary power loads assumed to be considered within the mechanical losses. In order to represent an EMS able to reduce the energy consumption of a vehicle when its AC system was in use, it was assumed a model that considers that the mass flow rate of the air was regulated by dynamically adjusting the blower speed and air-gates opening [19]. This model takes into account up to nine various heat and loads circumstances: (1) metabolic heat load; (2) direct solar radiation load; (3) diffuse solar radiation load; (4) radiation reflected by the road; (5) ambient load; (6) exhaust heat content; (7) engine heat; (8) ventilation load; and (9) evaporator heat [19]. Figure 5 depicts the AC system power consumption which determined by using a model in [19].

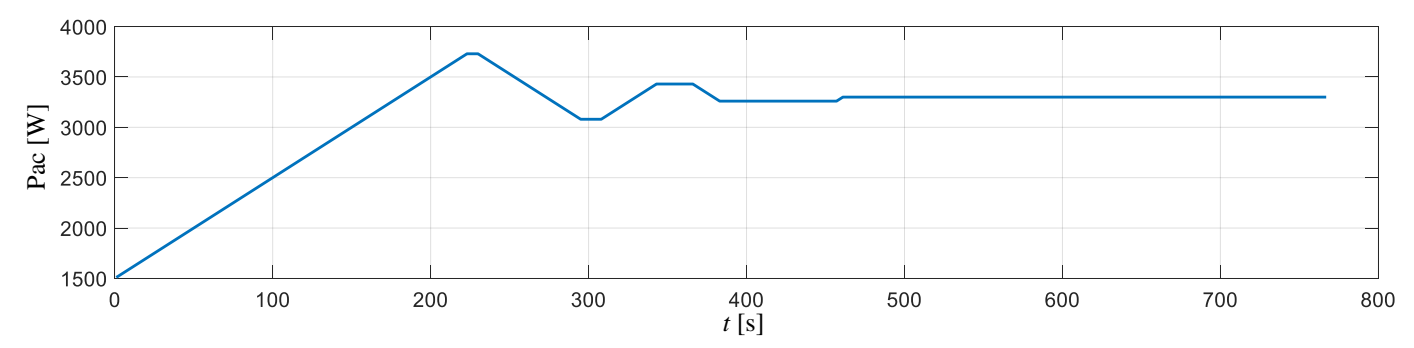

Figure 5. Power consumption of AC based on the model [19].

\subsection{Drive Cycle}

Driver behaviour has a significant effect on the fuel usage of the vehicle and the emissions released into the environment. A driving cycle depicting the velocity of a vehicle at different times was used to estimate the performance of vehicles in terms of fuel economy and exhaust emissions. For simulation purposes, the Highway Fuel Economy Test Cycle (HWFET) was used to present the driver behaviour, as shown in Figure 6.

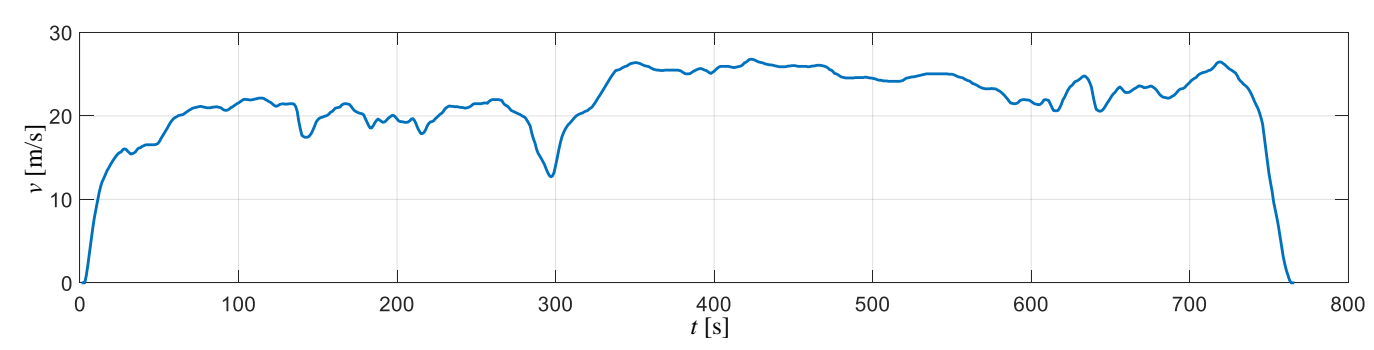

Figure 6. The standard driving cycle (HWFET).

\subsection{Model of Vehicle}

This study focused on finding a way to increase the engine efficiency of a CAV. The basic specification of the powertrain of the vehicle was shown in Table 1.

The characteristic of the ICE can be modelled as a nonlinear static map which relates its mass fuel rate consumption, $\dot{m}_{f u e l}$, speed of the engine, $\omega_{I C E}$, and its torque $\tau_{I C E}$. The model in this paper is represented as follows.

$$
\dot{m}_{f u e l}=\frac{\tau_{I C E} \omega_{I C E}}{\left(q_{\text {comb }}\right) \cdot \eta_{\text {mech }} \cdot \eta_{\text {eng }}}
$$

where $q_{c o m b}$ is the combustion energy, $\eta_{\text {mech }}=0.9$ [20] is the mechanical efficiency and $\eta_{\text {eng }}$ is the engine efficiency. 
The efficiency of the engine is represented by a contour plot, which was determined by the experimental characterization of the engine in real operating conditions, as a function of torque [Nm] and speed of the engine [rpm]. Due to thermodynamic limits for the ICE, the highest achievable efficiency was 34\%. Figure 7 depicts the contour plot of the engine model (Honda Insight (2004) 1.01 VTEC-E SI) used in this study.

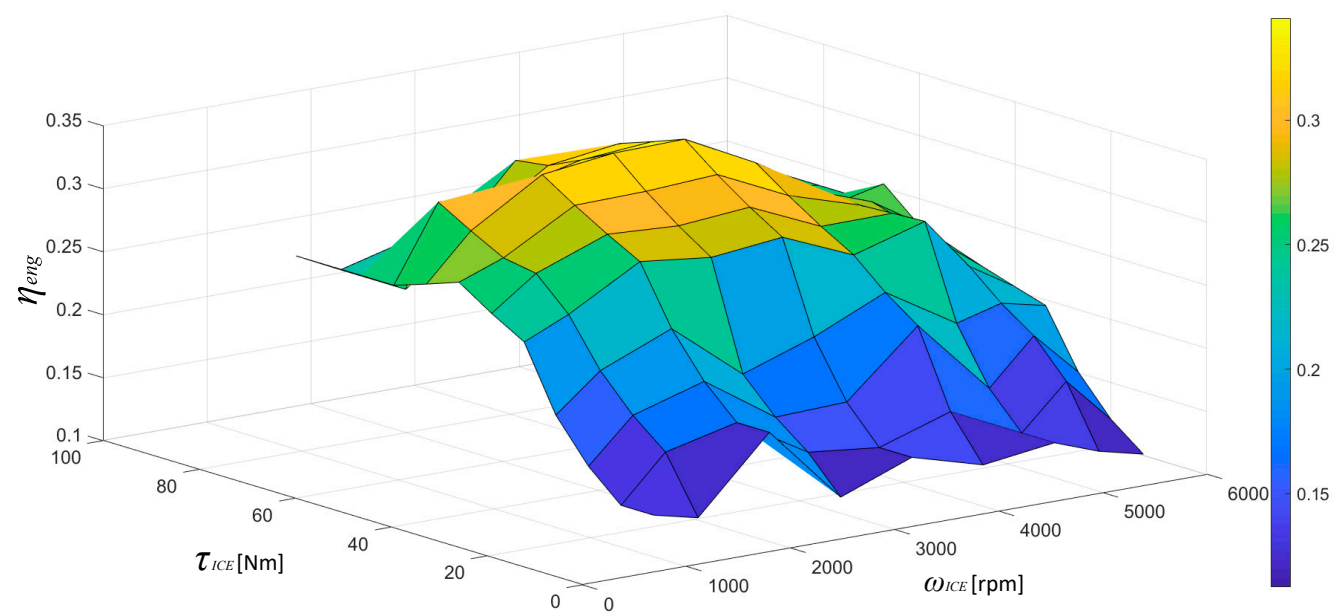

Figure 7. Engine efficiency map of Honda Insight (2004) 1.01 VTEC-E SI from ANL test data.

Table 1. Inputs to calculate $P_{R P D}$.

\begin{tabular}{ccc}
\hline Description & Symbol & Value \\
\hline Road friction coefficient & $c_{\text {rolling }}$ & 0.015 \\
Gravity acceleration & $g$ & $9.81\left(\mathrm{~m} / \mathrm{s}^{2}\right)$ \\
Vehicle speed & $v$ & $(\mathrm{~m} / \mathrm{s})$ \\
Wind speed & $v_{w}$ & $1280(\mathrm{~kg})$ \\
Mass (vehicle + equivalent & $m$ & 0.335 \\
rotating parts + passengers) & & $1.9 * 1 / \mathrm{cos}(\phi)$ \\
Drag coefficient (constant) & $c_{\text {drag }}$ & $1.225\left(\mathrm{~kg} / \mathrm{m}^{3}\right)$ \\
Cross-sectional area & $A$ & \\
Air density & $\rho$ & $38,017(\mathrm{~kJ} / \mathrm{kg})$ \\
Slope of the road & $\theta$ & $0.285(\mathrm{~m})$ \\
Combustion energy & $q_{c o m b}$ & $3.21: 1$ \\
Wheel radius & $r$ & $(\mathrm{rad} / \mathrm{s})$ \\
Differential ratio & $d_{r}$ & $(\mathrm{Nm})$ \\
Gear ratio & $g_{r}$ & $3.46: 11.75: 11.1: 10.86: 10.71: 1$ \\
Engine speed & $\omega_{I C E}$ & $1005.7(\mathrm{~J} / \mathrm{kg} . \mathrm{K})$ \\
Engine torque & $\tau_{I C E}$ & $19-60\left({ }^{\circ} \mathrm{C}\right)$ \\
\hline
\end{tabular}

\section{Energy Management System for a Conventional Autonomous Vehicle}

In this work, to enhance fuel efficiency and maintain vehicle performance, an EMS was designed, which is shown in Figure 8. The system has two main parts: an NF system and a PID throttle engine system. An NF system was utilized to create the optimal torque by considering the vehicle road power demand, which was calculated by using (4) as an input. A PID controller was applied to adjust the throttle of the engine to obtain a proper air to fuel ratio. Consequently, the engine was controlled to produce the desired torque, which follows the torque generated by the NF system. 


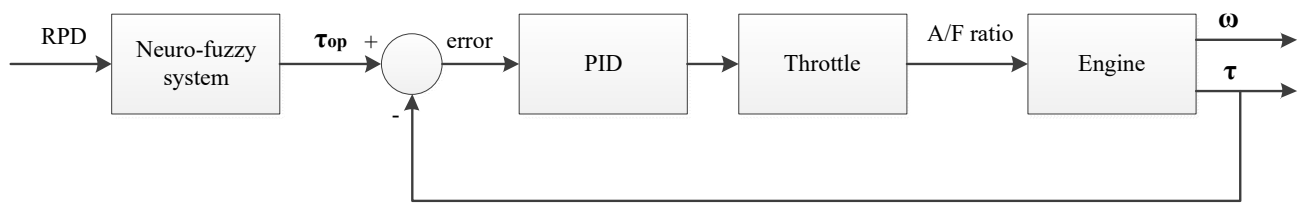

Figure 8. EMS architecture.

\subsection{NF System}

\subsubsection{Background}

The NF system was responsible for tuning and adjusting the parameters of the input-output of a fuzzy rule system by using human driving knowledge. The NF system can learn and tune parameters in a FIS by using a hybrid learning procedure. The fuzzy rules which supply the essential information on the comprehensive behaviour of the procedure were selected at each level of a neural network. The NF system considered in this study was an Adaptive-Network-based FIS which was one of the first NF systems investigated in [15].

\section{Structure of Adaptive NF Inference System}

According to the combination of fuzzy inference and artificial neural network, NF inferences were divided into two categories: the Mamdani system [21] and the Takagi-Sugeno system [22,23]. The former model has the form of a fuzzy set at the rule conclusion. The form of the latter model was a first-order linear equation at the rule conclusion for the input variable. The Tankagi-Sugeno model has advantages over the Mamdani model, including the efficiency in terms of computational ability, and the adaption in producing rules in combination with the optimal method of artificial neural network. Therefore, Takagi-Sugeno was chosen to be implemented in the NF system for the configuration of the fuzzy rules system in this study. The structure consists of five following layers, as shown in Figure 9.

Layer 1: Every node $i$ in this layer was adjustable with a node function as follows.

$$
O_{1, i}=\mu_{A_{i}}(x), i=1,2 ; O_{1, i}=\mu_{B_{i-2}}(y), i=3,4
$$

where $x$ (or $y$ ) is the input to node $i, A_{i}$ (or $B_{i-2}$ ) is the linguistic variable associated with the node membership function. $\mu_{A_{i}}(x)$ the membership function of $A_{i}$ is chosen as follows.

$$
\mu_{A_{i}}(x)=\frac{1}{1+\left[\left(\left(x-c_{i}\right) / a_{i}^{2}\right)\right]^{b i}}
$$

where $x$ is the input and $\left(a_{i}, b_{i}, c_{i}\right)$ is the premise set.

Layer 2: Each node in this layer is a fixed node, marked by circle node, with the node function to calculate the product of all incoming signal to serve as an output signal, is given by,

$$
O_{2, i}=\omega_{i}=\mu_{A_{i}}(x) \cdot \mu_{B_{i}}(y), i=1,2
$$

The output signal $\omega_{i}$ presents the firing strength of a rule.

Layer 3: Every node in this was also a fixed node, with the function to calculate the ratio of the i-th rule's firing strength to the sum of firing strengths of all the rules. The normalized firing strength produces the output for the i-th node, as follows.

$$
O_{3, i}=\bar{\omega}_{i}=\frac{\omega_{1}}{\omega_{1}+\omega_{2}}, i=1,2
$$


Layer 4: Every node in this layer is an adaptive node with the node function as below.

$$
O_{4}=\bar{\omega}_{i} f_{i}=\bar{\omega}_{i}\left(p_{i} x+q_{i} y+r_{i}\right), i=1,2
$$

where $\bar{\omega}_{i}$ is the output of layer 3 and $\left(p_{i}, q_{i}, r_{i}\right)$ is the consequent parameter set.

Layer 5: This layer composes a single fixed node with the node function computing the overall output by integrating all incoming signals.

$$
O_{5, i}=\sum \bar{\omega} f_{i}=\frac{\sum_{i} \omega_{i} f_{i}}{\sum_{i} \omega_{i}}
$$

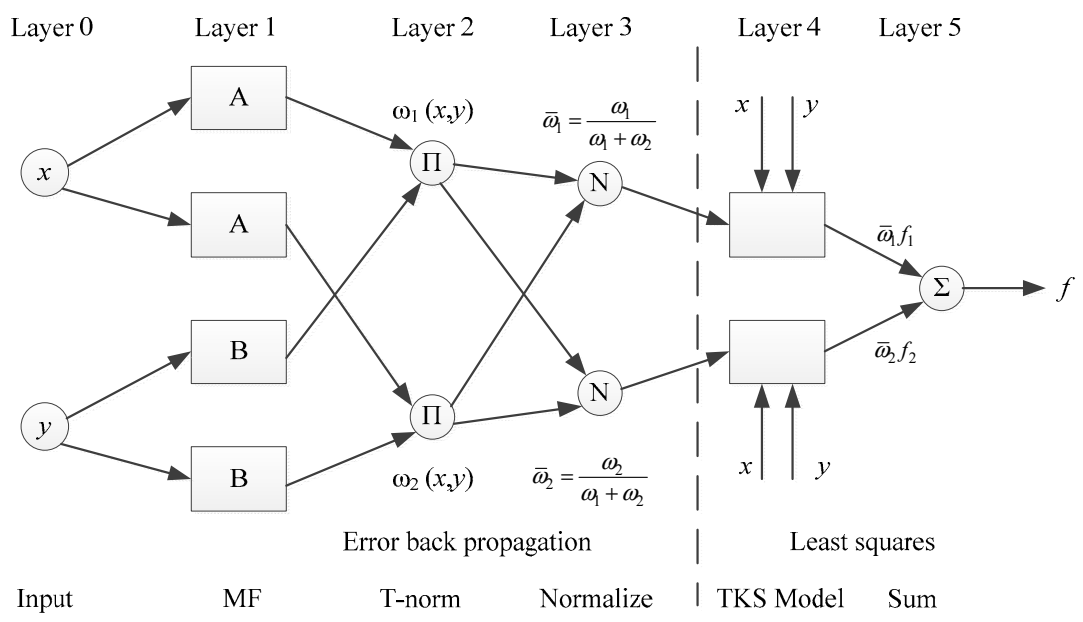

Figure 9. Structure of an NF system with Tagaki-Sugeno inference.

Learning Algorithm of the NF System

For the learning process, a hybrid learning algorithm that composed of a least square algorithm and a back-propagation method was used. The hybrid learning algorithm was used to update the conditional and conclusion parameters of the rule. Therefore, the error of the output can be lessened applying given input and output data. The main advantages of the hybrid learning algorithm are as follows.

1. The robustness of single training was not enough to guarantee the highest efficiency, training networks by hybrid learning can make the system smarter,

2. The performance of the network in supervised learning will decline if the algorithm breaks down. However, in a hybrid learning algorithm, the collapsing of the network can be recovered by one algorithm if another algorithm fails,

3. The training performance can be sped up by combining two or more algorithms.

FIS Generation Method

To generate the FIS, two main methods were used: the GP and the SC algorithm.

(a) GP algorithm

GP [24] is an algorithm in which space is divided into a grid-like configuration as depicted in Figure 10. It avoids overlapping areas in the space of the input. As this algorithm was used, the specific area containing the fuzzy rule was generated uniformly, leading to a smoother analysis of the fuzzy rule. It should be noted that the GP method is mainly suitable for the cases that have a small number of input variables. For instance, if there are $n$ input variables and each of them are divided into $m$ 
membership functions, the input space would need to be divided into an $m^{n}$ specific area, which is a very complicated structure if $n$ is big. Since the amount of input variables in this case was modest (one input variable) the GP algorithm can be successfully applied. Membership functions in FIS have different formats such as Gaussian, triangle, and trapezoidal, etc. In this case, the form of membership functions was assumed trapezoidal.

$$
\mu_{\mathrm{A}}(x)=\left\{\begin{array}{lr}
0 & x<\text { u or } x>v \\
\frac{x-u}{b-u} & u \leq x \leq b \\
1 & b \leq x \leq k \\
\frac{v-x}{v-k} & k \leq x \leq v
\end{array}\right.
$$

where $u, b, v, k$ are numerical parameters that present four heads of the trapezoidal.

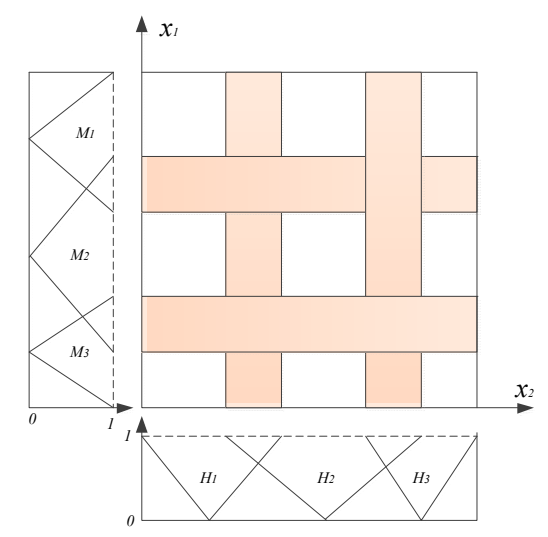

Figure 10. GP method.

(b) SC method

When the input variables of the system are increased, the number of rules go up exponentially. This means that the GP method was no longer suitable. The scatter partition method was exploited to solve the problem. By using a clustering algorithm, the input space was divided into $n$ clusters. The specific area was split by the number of $n$ clusters and the amount of each specific area determines the numbers of fuzzy rules. Thus, the number of groups was the number of the rules in the scattering partition algorithm. Based on the clustering method, scattering partition can be categorised into different kinds: SC [25,26], context-based fuzzy C-means clustering [27], and fuzzy C-means clustering [28].

In this study, the SC method as shown in Figure 11 was used. The procedure of the method is described as follows.

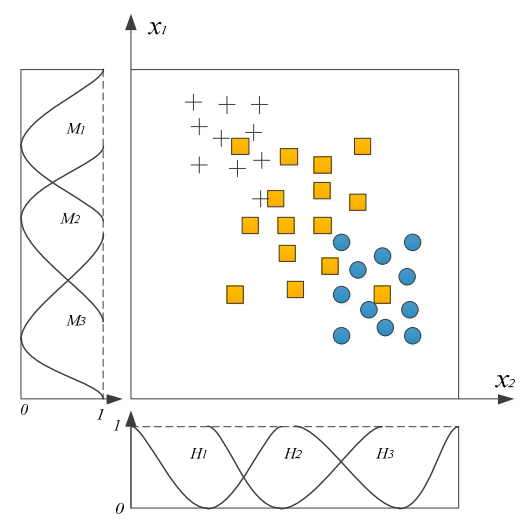

Figure 11. SC method. 
Step 1: The calculation of the density of each data point in the input space is formulated as follows,

$$
P_{k}=\sum_{j=1}^{K} \exp \left(-\frac{\left\|x_{k}-x_{j}\right\|}{\left(\frac{r_{a}}{2}\right)^{2}}\right)
$$

where $r_{a}$ is the radius of the cluster.

Step 2: The first cluster centre $u_{c 1}$ is determined by choosing the highest density value from $P_{k}$.

Step 3: The centre of the cluster in step above is revised as follows.

$$
P_{k}^{\prime}=P_{k}-P_{c 1} \exp \left(-\left(-\frac{\left\|x_{k}-u_{c 1}\right\|}{\left(\frac{r_{b}}{2}\right)^{2}}\right)\right)
$$

where $r_{b}$ is the radius of the elimination function, $r_{b}=1.5 r_{a}, P_{c 1}$ is the value of density measurement of $u_{c 1}$ estimated in Step 2.

Step 4: Two steps (2 and 3) were repeated up to the final condition met, i.e., until the highest density measurement was smaller than the predefined value.

\subsubsection{The NF System for a CAV}

In this paper, the NF system was constructed based on the Takagi-Sugeno Adaptive-Network-based FIS with one input (the road power demand of the vehicle), and one output (optimal torque). The input has three membership functions, leading to three rules for the whole system. The set of data, the road power demand and optimal torque, were obtained by performing many experiments. In order to train our model by pairing the input with the expected output, a training dataset was used. To predict the responses for the observations of the trained model, a validation step was performed followed by testing the algorithm on a test dataset to provide an unbiased evaluation of the performance of the final model. Currently, there is no standard method to split the data for these tasks [29]. However, based on our experiences [30], the dataset was randomly split into training $(70 \%)$, testing $(20 \%)$ and validation $(10 \%)$ to avoid overfitting and facilitate the development of a highly accurate model for future data. The performance results are shown in Figures 12 and 13. The FIS was generated in two cases: using the GP method and the SC method by using the hybrid learning algorithm as described above. The FISs of input which automatically generated by the NF system, are depicted in Figures 14 and 15.

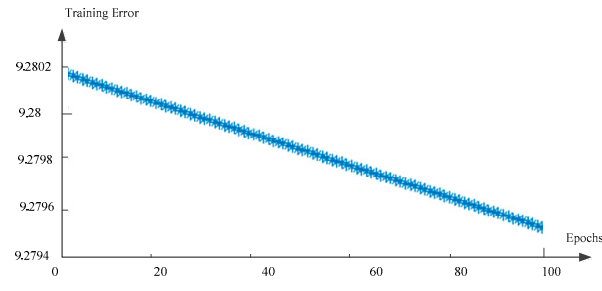

(a)

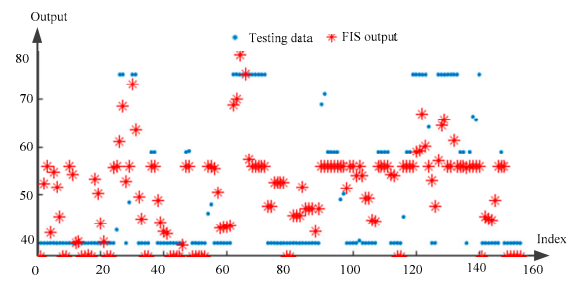

(c)

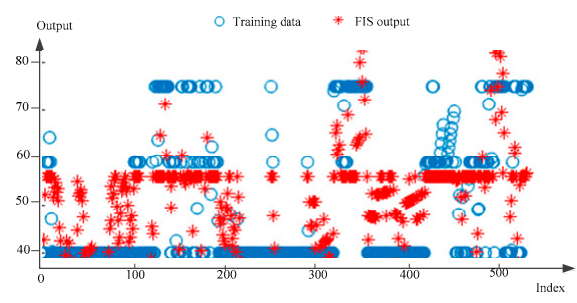

(b)

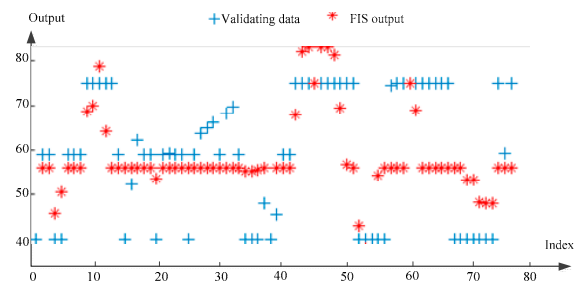

(d)

Figure 12. NF-SC: (a) Training error for 100 epochs with 0.01 error tolerance; (b) 70 percentage of dataset used for training, average error was 9.2795; (c) 20 percentage of dataset used for testing, average error was 9.6739; (d) 10\% of dataset used for validation; average error was 11.0469. 


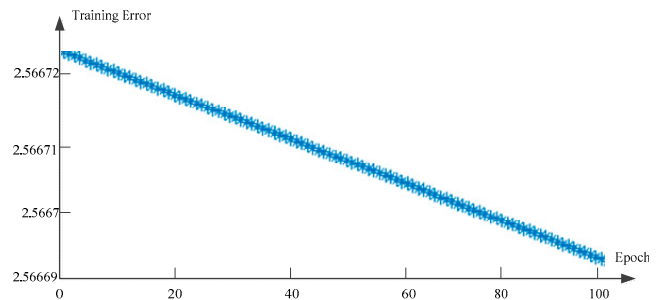

(a)

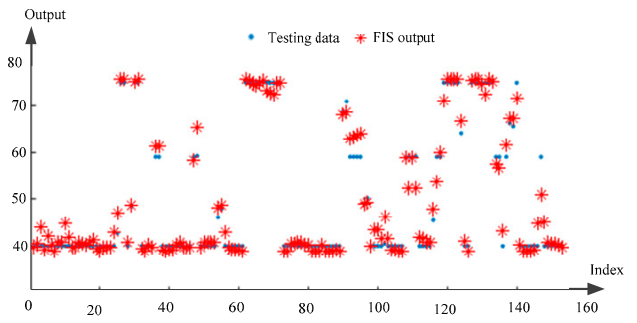

(c)

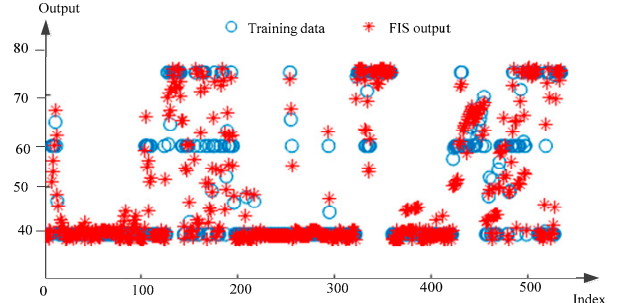

(b)

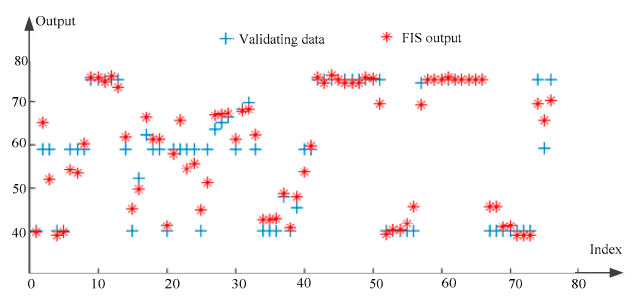

(d)

Figure 13. NF-GP: (a) Training error for 100 epochs with 0.01 error tolerance; (b) 70 percentage of dataset used for training, average error was 2.5667; (c) 20 percentage of dataset used for testing, average error was 2.1037; (d) 10 percentage of dataset used for validation, average error was 3.0907.

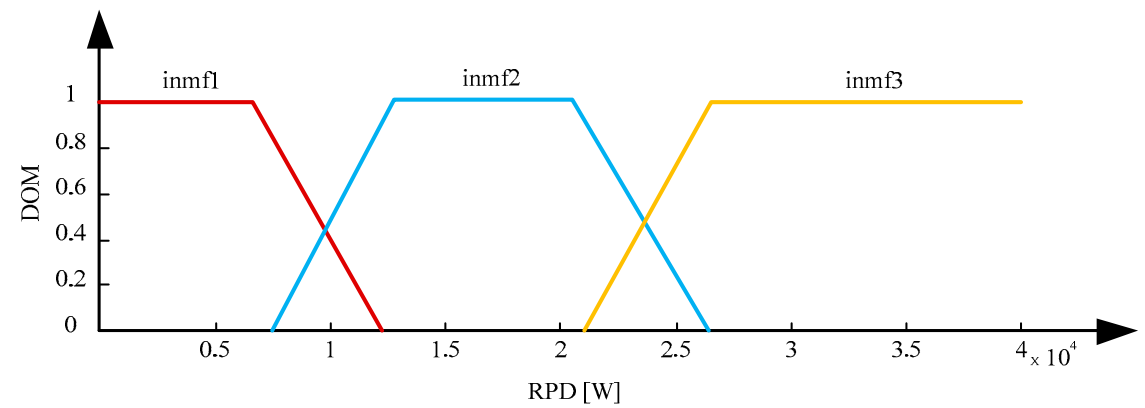

Figure 14. Membership functions of the input generated by the GP method.

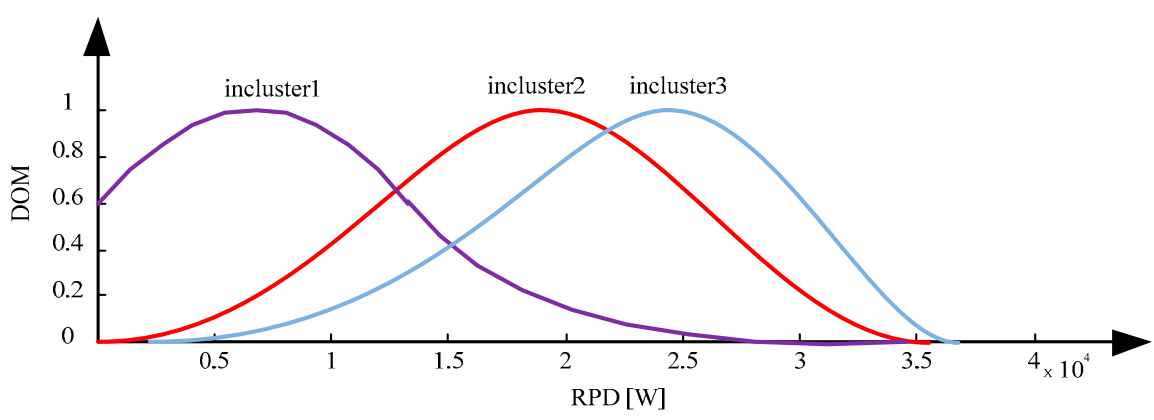

Figure 15. Membership functions of the input generated by the SC method.

\subsection{PID Controller and Throttle Engine System}

As can be seen in Figure 8, a PID controller was exploited to regulate the operation of the engine to follow the torque which produced by NF system. This process was implemented by adjusting the air mass flow rate into the cylinder of the engine. The error between preferred torque and actual torque was recognized as the input of the PID controller. The output of the PID controller is a function of A/F ratio that directly affect to the actual torque of the engine. The ICE is a Spark Ignition (SI) engine using gasoline [31]. Figure 16 illustrates a configuration of the gasoline engine dynamic system. The figure depicts air entering the intake manifold through the throttle mixes with the fuel from the injector to 
make a follow with controlled ratio, before entering the cylinder. Due to the combustion of fuel/air mixture, the pressure in the engine cylinder escalates, resulting in an amount of torque acting on the engine crankshaft.

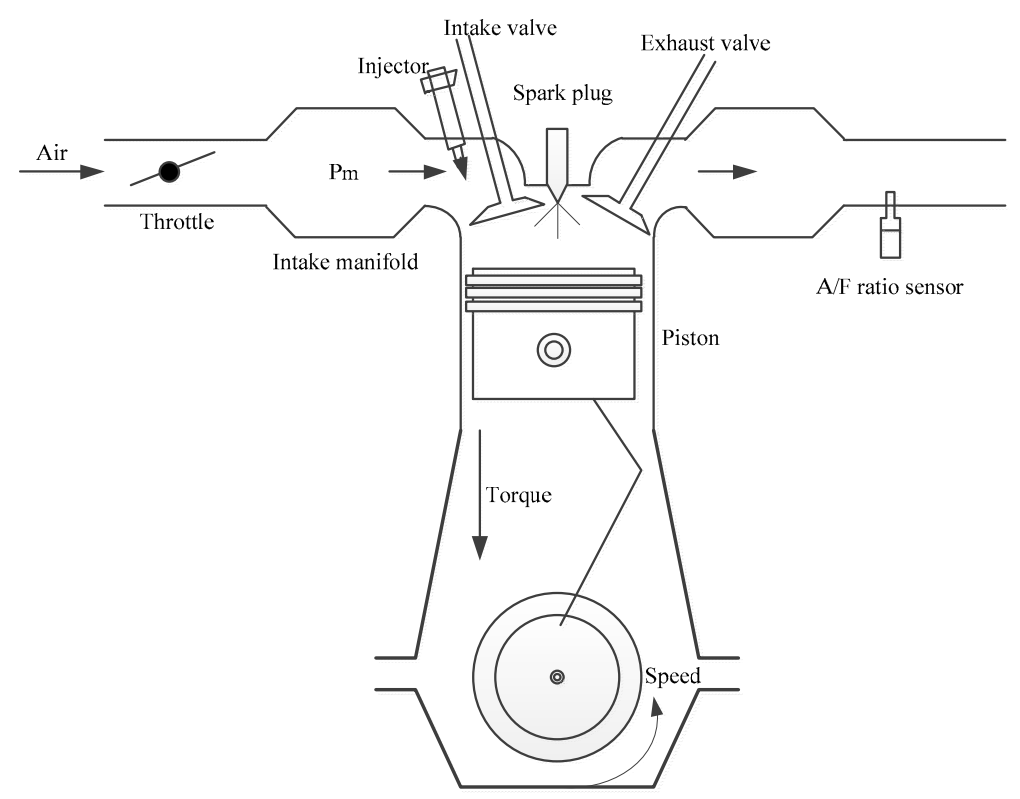

Figure 16. A configuration of spark ignition engine dynamic system.

The actual torque was calculated as follows.

$$
\tau=\frac{C_{T} \cdot \operatorname{AFI}(\lambda) \cdot \operatorname{SPI}(\delta) \cdot V_{\text {disp }} \cdot P_{m} \cdot \eta_{\text {vol }}}{4 \pi \cdot R \cdot T}
$$

where $C_{T}$ is torque constant, $A F I(\lambda)$ represents a function of air to fuel ratio, $\operatorname{SPI}(\delta)$ depicts the ignition time, $V_{\text {disp }}$ illustrates the engine volumetric displacement, $\eta_{v o l}$ is the engine volumetric efficiency, $P_{m}$ presents the manifold pressure. $A F I(\lambda)$ can be adopted in [32] as follows.

$$
\operatorname{AFI}(\lambda)=\cos (7.3834(A / F)-13.5)
$$

where $A / F$ is the air to fuel ratio. The $A / F$ is managed by means of proportional, integral and derivative actions in PID controller. PID regulator is formulated as follows.

$$
u(t)=k_{P} e(t)+k_{I} \int e(t) d t+k_{D} \frac{d e(t)}{d t}
$$

where $k_{P}$ is proportional, $k_{D}$ is the derivative, and $k_{I}$ is the integral parameters. The parameters $k_{P}, k_{D}$, $k_{I}$ were tuned manually in MATLAB Simulink by using the Ziegler-Nichols heuristic method which generated the three PID gain parameters such that the difference between the generated torque by NF system and the actual torque after PID controller converged to zero. The three PID gain parameters were also tuned by using the neural network method as given in [33]. Finally, the best three parameters were $3.01,1.01,1.001$ for $k_{P}, k_{I}$ and $k_{D}$, respectively.

\section{Simulation Results and Discussions}

\subsection{Simulations}

Simulation 1: The fuel usage of a vehicle was calculated for a period of $766 \mathrm{~s}$ equal to $16.5 \mathrm{~km}$, incompliance with a standard driving cycle (HWFET). The EMS based on NF system was introduced 
to regulate the engine working on the optimal torque area. All the data about the environmental condition, driver behaviour and vehicle specification were involved in EMS. In this case, the fuzzy logic controller used the FIS generated by the GP method which was called NF-GP.

Simulation 2: This simulation was conducted with the same conditions as simulation 1. However, the fuzzy logic controller used the FIS generated by the SC method and this was named NF-SC.

\subsection{Discussions}

With the FIS generated by the NF-GP, the EMS governed the engine torque within a range of $38-85[\mathrm{Nm}]$, as was shown in Figure 17. The revolutions per minute of the engine was depicted in Figure 18. The proper A/F ratio controlled by the PID controller to produce the actual torque of the engine is illustrated in Figure 19. With these amounts of the torque and revolutions per minute, the engine was guaranteed to operate in the higher efficiency area, as demonstrated in Figure 20. In this simulation, the average efficiency of the energy was $29.64 \%$ leading to the fuel usage of the vehicle being $6.35 \mathrm{l} / 100 \mathrm{~km}$. The energy usage rate is illustrated in Figure 21.

Meanwhile, with the FIS generated by the NF-SC, the torque of the engine falls in the range 38-76 (Nm), as illustrated in Figure 17. Figure 18 shows the revolutions per minute of the engine generated by the NF-SC. Figure 19 represents the proper A/F ratio adjusted by the PID controller to provide the actual torque. With these amounts of torque and revolutions per minute, the engine operated in the lower efficiency area compared with the above case, as was shown in Figure 20. In this simulation, the average fuel efficiency of the engine was $28.44 \%$. Consequently, the fuel consumption of the vehicle escalated to 6.69 for $100 \mathrm{~km}$ distance of traverse.

The performance of the EMSs based on the NF system was also compared with the existing EMSs which are listed in Table 2. In [5], EMSs was constructed based on the fuzzy logic system in which membership functions were tuned manually and optimized by Particle Swarm Optimization (PSO).

Table 2. Fuel consumption comparison of different EMSs for CAV.

\begin{tabular}{cccc}
\hline Model (CAV) & Distance & Average $\eta_{\text {eng }} \mathbf{( \% )}$ & $\left.\boldsymbol{m}_{\text {fuel }} \mathbf{( L / 1 0 0 ~} \mathbf{~ k m}\right)$ \\
\hline Without controller & $16.5 \mathrm{~km}$ & 25.35 & 7.2 \\
FLS & $16.5 \mathrm{~km}$ & 28.39 & 6.71 \\
FLS + PSO & $16.5 \mathrm{~km}$ & 29.09 & 6.51 \\
NF-SC & $16.5 \mathrm{~km}$ & 28.44 & 6.69 \\
NF-GP & $16.5 \mathrm{~km}$ & 29.64 & 6.35 \\
\hline
\end{tabular}

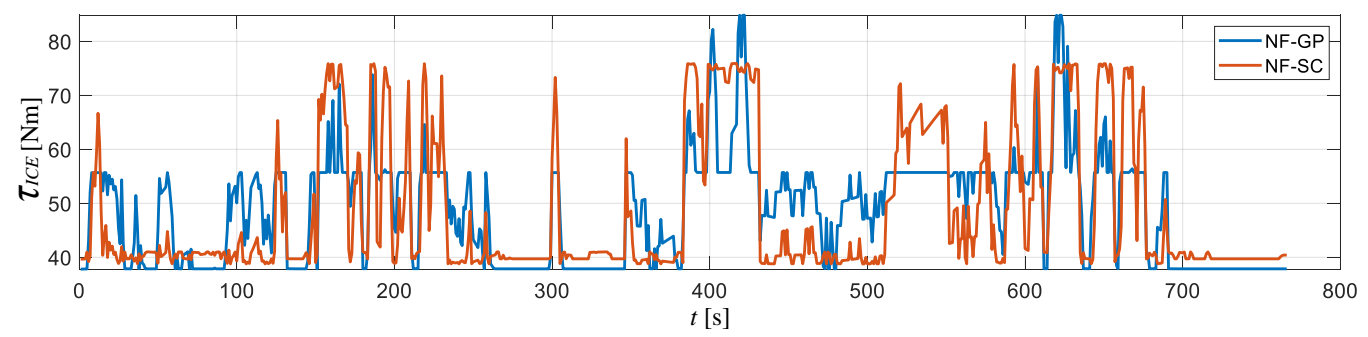

Figure 17. The engine torque generated by NF-GP and NF-SC methods. 


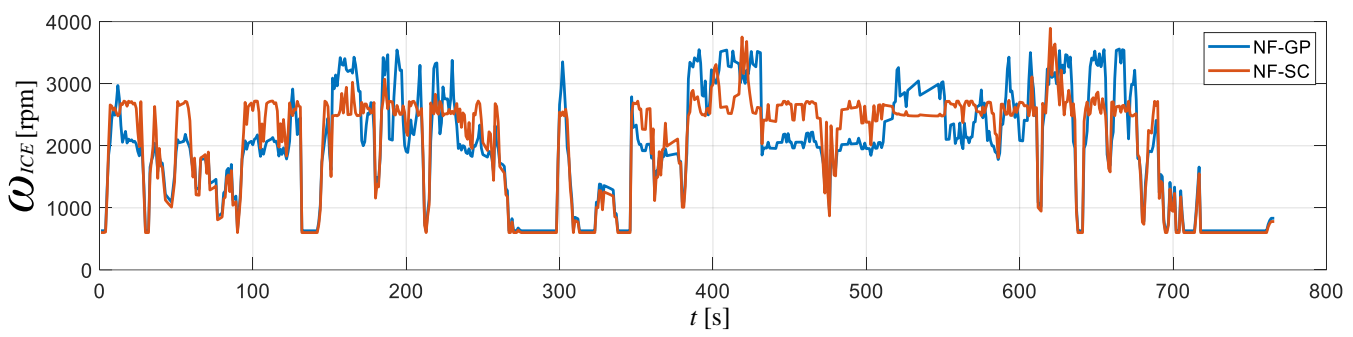

Figure 18. The revolutions per minute of the engine generated by NF-GP and NF-SC methods.

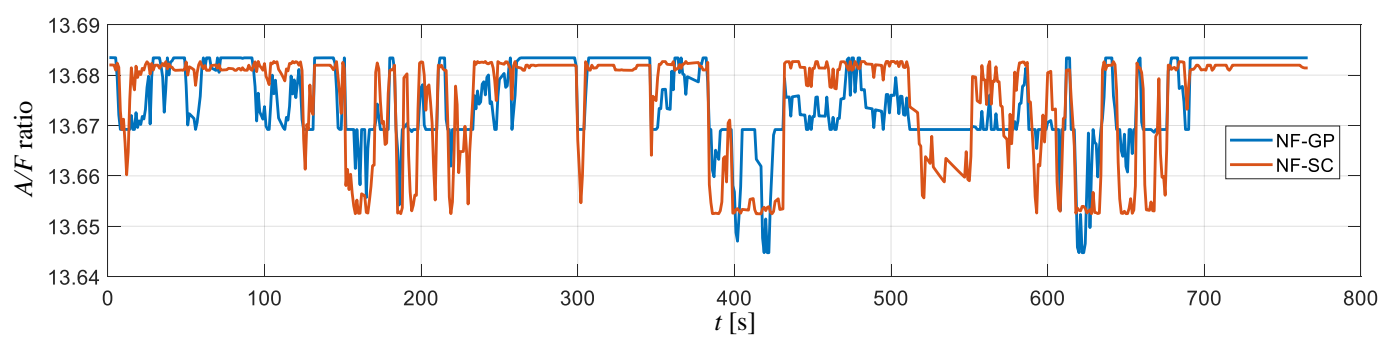

Figure 19. The A/F ratio by NF-GP and NF-CS methods.

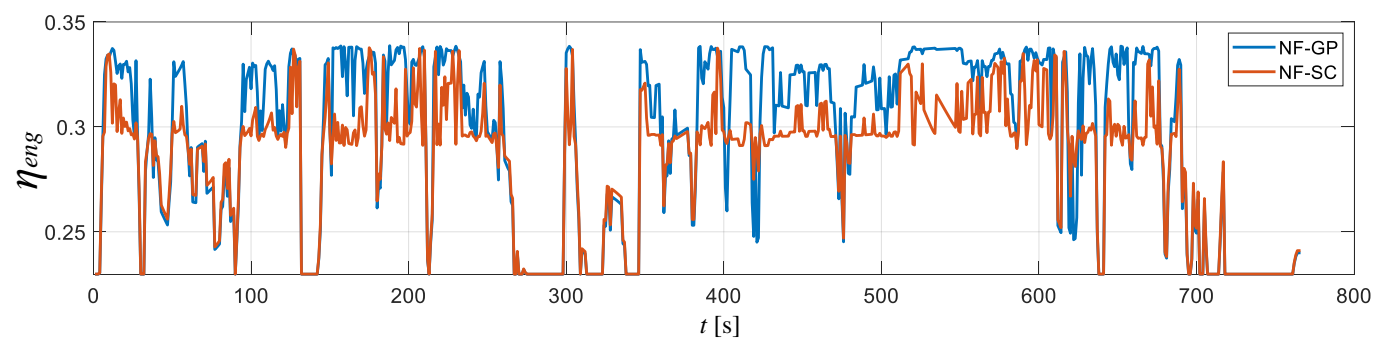

Figure 20. The engine efficiency by NF-GP and NF-SC methods.

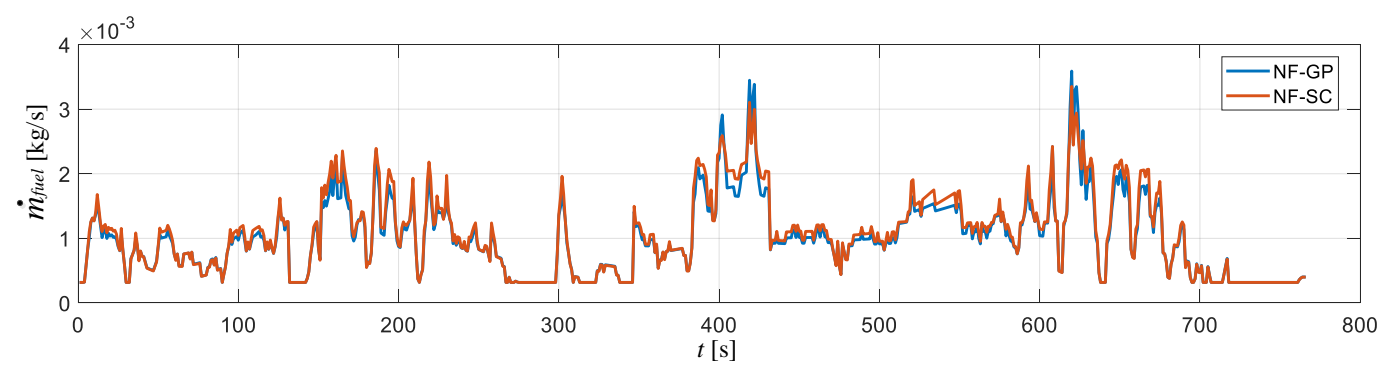

Figure 21. The fuel consumption rate of the engine by NF-GP and NF-SC methods.

\section{Conclusions}

In this paper, a NF system for energy management of a CAV was proposed. The EMS of CAV considered the driver behaviour, environment and vehicle operation. The Highway Fuel Economy Test Cycle (HWFET) was used to present the driver behaviour. The environment model was included slope road, wind direction and wind speed where they were dynamically changed. The EMS combined the NF system and the PID throttle engine system to reduce energy consumption for a CAV. The NF system used RPD as input to generate the optimal torque for the engine. The PID controller adjusted the throttle of the engine to obtain the proper $\mathrm{A} / \mathrm{F}$ ratio to produce desired torque.

The performance of the proposed EMS in terms of fuel consumption was analysed and compared for two NF models using different input space partitioning methods: GP and SC. The results showed that the performance of the NF-GP was better than the performance of NF-SC. The underlying reason was that the number of input variables in the system were small. The fuel consumption was $7.21 / 100 \mathrm{~km}$ 
for the case without controller, $6.691 / 100 \mathrm{~km}$ for the NF-SC case (or 7.08\% reduction), and 6.35 1/100 km for the NF-GP case (or an $11.8 \%$ reduction).

Author Contributions: D.P. conceptualization, data curation, formal analysis, methodology, writing-original draft; A.B.-H. supervision, writing—review \& editing; R.H. supervision, writing—review \& editing; R.N.J. supervision, writing-review \& editing; A.D. formal analysis, writing-review \& editing; A.J. formal analysis, software, validation, writing — review \& editing; D.B.P. validation, writing-review \& editing; H.K Conceptualization, methodology, supervision, formal analysis, writing-review \& editing. All authors have read and agreed to the published version of the manuscript.

Funding: This research received no external funding.

Conflicts of Interest: Authors did have any conflicts of interest.

\section{Nomenclature}

$\begin{array}{clcl}\tau_{\text {ICE }} & \text { Engine torque }(\mathrm{Nm}) & A / F & \text { Air to fuel ratio } \\ \omega_{I C E} & \text { Engine speed }(\mathrm{rpm}) & P_{m} & \text { Manifold pressure } \\ \theta & \text { Slope of the road (degree) } & v_{t} & \text { Speed of vehicle at time } t(\mathrm{~m} / \mathrm{s}) \\ \rho & \text { Air density }\left(\mathrm{kg} / \mathrm{m}^{3}\right) & v_{w} & \text { Absolute wind speed }(\mathrm{m} / \mathrm{s}) \\ \eta_{m e c h} & \text { Mechanical efficiency } & V_{d i s p} & \begin{array}{l}\text { Volumetric displacement of the } \\ \text { engine }\left(\mathrm{m}^{3}\right)\end{array} \\ \eta_{e n g} & \text { Engine efficiency } & \text { AC } & \text { Air Conditioning } \\ \dot{m}_{f u e l} & \text { Mass flow rate consumption }(\mathrm{kg} / \mathrm{s}) & \text { AV } & \text { Autonomous Vehicle } \\ P_{a c} & \text { Air conditioning power }(\mathrm{W}) & \text { CAV } & \text { Conventional Autonomous } \\ c_{d} & \text { Drag coefficient } & \text { Vehicle } \\ c_{r} & \text { Road friction coefficient } & \text { EMS } & \text { Energy Management System } \\ C_{T} & \text { Constant torque } & \text { FIS } & \text { Fuzzy Inference System } \\ A(\phi) & \text { Cross-sectional area }\left(\mathrm{m}^{2}\right) & \text { HEV } & \text { Hybrid Electric Vehicle } \\ A F I(\lambda) & \text { Function of air to fuel ratio } & \text { ICE } & \text { Internal Combustion Engine } \\ g_{r} & \text { Gear ratio of the gear box } & \text { RPD } & \text { Road Power Demand }(\mathrm{W}) \\ d_{r} & \text { Differential ratio } & \text { NF } & \text { Neuro-Fuzzy } \\ r & \text { Wheel radius }(\mathrm{m}) & \text { GP } & \text { Grid Partition } \\ & & \text { SC } & \text { Subtractive Clustering }\end{array}$

\section{References}

1. Khayyam, H.; Javadi, B.; Jalili, M.; Jazar, R.N. Artificial Intelligence and Internet of Things for Autonomous Vehicles. In Nonlinear Approaches in Engineering Applications; Dai, R., Ed.; Springer: Cham, Switzerland, 2019.

2. Marzbani, H.; Khayyam, H.; To, C.N.; Quoc, Đ.V.; Jazar, R.N. Autonomous Vehicles: Autodriver Algorithm and Vehicle Dynamics. IEEE Trans. Veh. Technol. 2019, 68, 3201-3211. [CrossRef]

3. Miao, H.; Jia, H.; Li, J.; Qiu, T.Z. Autonomous connected electric vehicle (ACEV)-based car-sharingsystem modeling and optimal planning: A unified two-stage multi-objective optimization methodology. Energy 2019, 169, 797-818. [CrossRef]

4. Jazar, R.N.; Dai, L. Nonlinear Approaches in Engineering Applications: Automotive Applications of Engineering Problems; Springer: Cham, Switzerland, 2019.

5. Phan, D.; Bab-Hadiashar, A.; Lai, C.Y.; Crawford, B.; Hoseinnezhad, R.; Jazar, R.N.; Khayyam, H. Intelligent energy management system for conventional autonomous vehicles. Energy 2020, 191, 116476. [CrossRef]

6. Khayyam, H.; Kouzani, A.Z.; Khoshmanesh, K.; Hu, E.J. A rule-based intelligent energy management system for an internal combustion engine vehicle. In Proceedings of the TENCON 2008-2008 IEEE Region 10 Conference, Hyderabad, India, 19-21 November 2008.

7. Marano, V.; Rizzoni, G.; Tulpule, P.; Gong, Q.; Khayyam, H. Intelligent energy management for plug-in hybrid electric vehicles: The role of ITS infrastructure in vehicle electrification. Oil Gas Sci. Technol. Rev. D'ifp Energ. Nouv. 2012, 67, 575-587. [CrossRef]

8. Khayyam, H.; Bab-Hadiashar, A. Adaptive intelligent energy management system of plug-in hybrid electric vehicle. Energy 2014, 69, 319-335. [CrossRef] 
9. Khayyam, H.; Kouzani, A.Z.; Hu, E.J. An intelligent energy management model for a parallel hybrid vehicle under combined loads. In Proceedings of the 2008 IEEE International Conference on Vehicular Electronics and Safety, Columbus, OH, USA, 22-24 September 2008.

10. Koot, M.; Kessels, J.T.; De Jager, B.; Heemels, W.; Van den Bosch, P.; Steinbuch, M. Energy management strategies for vehicular electric power systems. IEEE Trans. Veh. Technol. 2005, 54, 771-782. [CrossRef]

11. Koot, M.; Kessels, J.; De Jager, B.; Van Den Bosch, P. Fuel reduction potential of energy management for vehicular electric power systems. Int. J. Altern. Propuls. 2006, 1, 112-131. [CrossRef]

12. Won, J.-S.; Langari, R. Intelligent energy management agent for a parallel hybrid vehicle-part II: Torque distribution, charge sustenance strategies, and performance results. IEEE Trans. Veh. Technol. 2005, 54, 935-953. [CrossRef]

13. Poursamad, A.; Montazeri, M. Design of genetic-fuzzy control strategy for parallel hybrid electric vehicles. Control Eng. Pract. 2008, 16, 861-873. [CrossRef]

14. Khayyam, H.; Nahavandi, S.; Davis, S. Adaptive cruise control look-ahead system for energy management of vehicles. Expert Syst. Appl. 2012, 39, 3874-3885. [CrossRef]

15. Jang, J.-S. ANFIS: Adaptive-network-based fuzzy inference system. IEEE Trans. Syst. ManCybern. 1993, 23, 665-685. [CrossRef]

16. Babuška, R.; Verbruggen, H. Neuro-fuzzy methods for nonlinear system identification. Annu. Rev. Control 2003, 27, 73-85. [CrossRef]

17. Khayyam, H. Stochastic models of road geometry and wind condition for vehicle energy management and control. IEEE Trans. Veh. Technol. 2013, 62, 61-68. [CrossRef]

18. Lambert, M.; Jones, B. Automotive adsorption air conditioner powered by exhaust heat. Part 1: Conceptual and embodiment design. Proc. Inst. Mech. Eng. Part D J. Automob. Eng. 2006, 220, 959-972. [CrossRef]

19. Khayyam, H.; Kouzani, A.Z.; Hu, E.J. Reducing energy consumption of vehicle air conditioning system by an energy management system. In Proceedings of the IEEE Intelligent Vehicles Symposium, Xi'an, China, 3-5 June 2009.

20. Michael, P.; Anthony, M. Engine Testing Theory and Practice; SAE International: Warrendale, PA, USA, 1999.

21. Mamdani, E.H.; Assilian, S. An experiment in linguistic synthesis with a fuzzy logic controller. Int. J. Man Mach. Stud. 1975, 7, 1-13. [CrossRef]

22. Sugeno, M.; Kang, G. Structure identification of fuzzy model. Fuzzy Sets Syst. 1988, 28, 15-33. [CrossRef]

23. Takagi, T.; Sugeno, M. Fuzzy identification of systems and its applications to modeling and control. IEEE Trans. Syst. ManCybern. 1985, 116-132. [CrossRef]

24. Jang, J.-S.R.; Sun, C.-T.; Mizutani, E. Neuro-fuzzy and soft computing-a computational approach to learning and machine intelligence [Book Review]. IEEE Trans. Autom. Control 1997, 42, 1482-1484. [CrossRef]

25. Chiu, S.L. Fuzzy model identification based on cluster estimation. J. Intell. Fuzzy Syst. 1994, 2, $267-278$. [CrossRef]

26. Yager, R.R.; Filev, D.P. Generation of fuzzy rules by mountain clustering. J. Intell. Fuzzy Syst. 1994, 2, $209-219$. [CrossRef]

27. Pedrycz, W. Conditional fuzzy c-means. Pattern Recognit. Lett. 1996, 17, 625-631. [CrossRef]

28. Bezdek, J.C. Pattern Recognition with Fuzzy Objective Function Algorithms; Springer Science \& Business Media: New York, NY, USA, 2013.

29. Kuhn, M.; Johnson, K. Feature Engineering and Selection: A Practical Approach for Predictive Models; CRC Press: Boca Raton, FL, USA, 2019.

30. Khayyam, H.; Golkarnarenji, G.; Jazar, R.N. Limited data modelling approaches for engineering applications. In Nonlinear Approaches in Engineering Applications; Springer: Cham, Switzerlnad, 2018; pp. 345-379.

31. Heywood, J.B. Internal Combustion Engine Fundamental; McGraw Hill: New York, NY, USA, 1988.

32. Cho, D.; Hedrick, J.K. Automotive powertrain modeling for control. J. Dyn. Sys. Meas. Control. 1989, 111, 568-576. [CrossRef]

33. Khayyam, H.; Kouzani, A.Z.; Hu, E.J.; Nahavandi, S. Coordinated energy management of vehicle air conditioning system. Appl. Therm. Eng. 2011, 31, 750-764. [CrossRef]

(C) 2020 by the authors. Licensee MDPI, Basel, Switzerland. This article is an open access article distributed under the terms and conditions of the Creative Commons Attribution (CC BY) license (http://creativecommons.org/licenses/by/4.0/). 